\title{
PENGGUNAAN MODEL POE2WE BERBASIS METODE MIND MAPPING SEBAGAI PENINGKATAN PEMBELAJARAN DALAM PROSES SAINS
}

\author{
${ }^{1}$ Safitri Dina Prameswari ${ }^{2}$ Nana \\ Program Studi Pendidikan Fisika \\ Fakultas Keguruan dan Ilmu Pendidikan Universitas Siliwangi \\ Jln. Siliwangi No. 24 Tasikmalaya \\ Safitridina124@gmail.com \\ nana@unsil.ac.id
}

\begin{abstract}
Abstrak
Penelitian ini bertujuan untuk (1) Mengetahui kegunaan model $\mathrm{POE}_{2} \mathrm{WE}$ (2) Memberikan solusi untuk meningkatkan inovasi belajar salah satunya dengan menggunakan mind mapping (3) meningkatkan minat belajar siswa terhadap sains . Dalam melaksanakan penelitian tersebut, digunakan strategi model pembelajaran $\mathrm{POE}_{2} \mathrm{WE}$ yang sesuai untuk metode mind mapping yang merupakan teknik yang dapat meningkatkan cara merekam informasi. Dengan menggunakan peta pikiran, pembuat dapat dengan cepat mengidentifikasi dan memahami struktur subjek. pembaca dapat melihat potongan-potongan informasi yang tepat, serta merekam fakta-fakta yang terkandung dalam catatan yang normal. Lebih dari itu, peta pikiran mendorong pemecahan masalah secara kreatif, karena mereka menyimpan informasi dalam format. Mind mapping dapat disusun dengan berbasis model $\mathrm{POE}_{2} \mathrm{WE}$ dengan melakukan proses memetakan pikiran dalam menghubungkan konsep-konsep permasalahan tertentu dari cabang-cabang topik membentuk korelasi konsep menuju pada suatu pemahaman dan hasilnya ditungkan langsung di atas kertas dengan animasi yang disukai dan mudah dimengerti oleh pembuat maupun pembacanya. Sehingga tulisan yang dihasilkan merupakan gambaran langsung dari cara kerja berbagaoi topik yang dipetakan secara menarik dan sistematis.
\end{abstract}

Kata kunci: $\mathrm{POE}_{2} \mathrm{WE}$, mind mapping, sains

\begin{abstract}
This study aims to (1) Know the usefulness of the POE2WE model (2) Provide solutions to improve learning innovation one of them by using mind mapping (3) increase student interest in learning about science. In carrying out this research, a POE2WE learning model strategy is used that is appropriate for the mind mapping method which is a technique that can improve the way information is recorded. By using mind maps, makers can quickly identify and understand the structure of the subject. the reader can see the right pieces of information, as well as record the facts contained in the normal notes. More than that, mind maps encourage creative problem solving, because they store information in a format. Mind mapping can be compiled on the basis of the POE2WE model by mapping the mind in linking certain problem concepts from topic branches to form a concept correlation to an understanding and the results are set directly on paper with animations that are liked and easily understood by the creator or reader. So the
\end{abstract}


writing produced is a direct description of the workings of various topics that are mapped in an interesting and systematic way.

Keywords: POE2WE, mind mapping, science

\section{Pendahuluan}

Pendidikan dapat dipandang sebagai esensi kehidupan baik itu bagi perkembangan pribadi maupun masyarakat untuk menghadapi harapan dan tantangan masa depan yang lebih baik. Tujuan utama pendidikan adalah mengembangkan sepenuhnya bakat individu, mewujudkan potensi kreatif, pencapaian tujuan pribadi serta tanggung jawab pribadi terhadap kehidupan sosial dalam masyarakat. Guna mendukung pencapaian tujuan tersebut, perlu dikembangkan masyarakat belajar (learning society) pada setiap satuan dan jenjang pendidikan. Program pendidikan di sekolah harus mampu membangun lingkungan belajar bagi siswanya. Delors dkk. dalam International Commission on Education for the Twenty-First Century, Report to UNESCO (1996) telah merekomendasikan empat pilar untuk mewujudkan pendidikan masa depan yang lebih baik yaitu: (1) Learning to know, belajar mengetahui termasuk belajar bagaimana belajar; (2) Learning to do, belajar berbuat sesuatu; (3) Learning to be, belajar menjadi seseorang: serta (4) Learning to life together, belajar hidup bersama dengan orangorang lain. Program pendidikan di sekolah hendaklah memperhatikan empat pilar tersebut dengan menjawab empat pertanyaan yaitu: (1) Melalui program pendidikan tertentu, pengetahuan dan informasi fungsional mana yang harus disampaikan kepada peserta didik; (2) Bagaimana tata cara berbuat yang harus dikuasai peserta didik (kompetensi dan keterampilan) dengan memperhatikan pengetahuan dan informasi yang sudah diketahuinya; (3) Bagaimana informasi dan pengetahuan diinternalisasikan dan menjadi bagian dari pembentukan diri dan pembaharuan diri; serta (4) Bagaimana informasi dan pengetahuan yang dimiliki termasuk pengalaman berbuat dapat dijadikan modal untuk hidup dengan sesama manusia dalam suasana kondusif.

Implementasi keempat pilar tersebut dengan sendirinya akan berorientasi pada kepentingan dan kebutuhan peserta didik serta akan menghasilkan manusia terdidik yang mampu membangun masyarakatnya. Hasil identifikasi terhadap kondisi obyektif pembelajaran di sekolah saat ini menunjukkan permasalahan antara lain: (1) Banyak siswa mampu menyajikan tingkat hapalan yang baik terhadap materi pelajaran yang diterimanya, tetapi pada kenyataannya tidak memahaminya; (2) Sebagian besar dari siswa tidak mampu menghubungkan antara apa yang mereka pelajari dengan bagaimana pengetahuan tersebut akan dipergunakan/dimanfaatkan; serta (3) Siswa memiliki kesulitan untuk memahami konsep akademik sebagaimana mereka biasa diajarkan yaitu dengan menggunakan sesuatu yang abstrak dengan metode ceramah (Depdiknas, 2007). Padahal di sisi lain, siswa sangat membutuhkan pemahaman konsep yang berhubungan dengan aktivitas kehidupan di masyarakat di mana mereka akan menjalani kehidupan dan bekerja.

Uraian di atas menunjukkan bahwa kurikulum dan pembelajaran IPA yang berlaku di sekolah-sekolah harus terus dikaji dan dikembangkan sehingga menghasilkan kurikulum dan 
model pembelajaran yang sesuai dengan tuntutan perkembangan zaman serta dapat dipahami oleh para pelaku pendidikan untuk diterapkan pada situasi sesungguhnya. Terkait dengan hal tersebut, banyak upaya telah dilakukan untuk meningkatkan mutu pembelajaran IPA antara lain perbaikan kurikulum, penggunaan strategi dan metode pembelajaran, serta peningkatan kualitas guru melalui program pelatihan. Namun upaya tersebut belum menunjukkan dampak perbaikan yang signifikan. Inovasi strategi dan metode pembelajaran IPA yang dilakukan guru di kelas biasanya kurang berhasil karena dalam implementasinya kurang memperhatikan karakteristik siswa, termasuk perkembangan kemampuan berpikirnya (Jeremy, 2005). Sejalan dengan pemikiran di atas, dewasa ini muncul kecende-rungan terjadinya pergeseran filosofi pembelajaran, yaitu dari paradigma transmisi menuju pada aktivitas kelas yang berpusat pada pembelajar (O’Malley \& Fierce, 1996).

Pergeseran filosofi tersebut berorientasi pada pembelajaran yang lebih memperhatikan perkembangan siswa meliputi pertumbuhan fisik, sosial, emosional, dan intelektual. Hal ini menghendaki adanya pergeseran peran siswa dari posisi sebagai pengamat informasi yang pasif menjadi pembelajar aktif, pemikir kritis dan kreatif dalam menganalisis serta mengaplikasikan konsep yang dipelajarinya untuk memecahkan masalah. Kemampuan pemecahan masalah pada dasarnya merupakan hakekat tujuan pembelajaran yang menjadi kebutuhan siswa dalam menghadapi kehidupan nyata.

\section{Metode Penelitian}

Penelitian ini menggunakan metode studi pustaka, dengan mengkaji beberapa teori dasar yang relevan dengan topik yang akan dibahas, menggali teori-teori yang relevan dengan pembahasan pada penelitian dan melakukan komparasi untuk menemukan konsep-konsep yang sesuai dengan pokok masalah yang dibahas tentang penggunaan model POE2WE. Dan juga untuk menemukan suatu masalah untuk diteliti, dalam arti bukti-bukti atau pernyataan bahwa masalah yang akan diteliti belum terjawab atau belum terpecahkan secara memuaskan atau belum pernah diteliti orang mengenai tujuan, data dan metode, analisa dan hasil untuk waktu dan tempat yang sama. Dalam membahas suatu topik dengan menggunakan studi pustaka berupa jurnal, buku ataupun artikel untuk menguji kebenaran topik yang diteliti.

\section{Hasil Penelitian dan Pembahasan}

\section{A. Model POE2WE}

Model pembelajaran Prediction, Observation, Explanation, Elaboration, Write dan Evaluation (POE2WE) dikembangkan dari model pembelajaran POEW dan model pembelajaran Fisika dengan Pendekatan Konstruktivistik. Pengembangan ini dilakukan untuk sebagai penyempurnaan kedua model sebelumnya. Model POE2WE merupakan model pembelajaran yang dikembangkan untuk mengetahui pemahaman peserta didik mengenai suatu konsep dengan pendekatan konstruktivistik. Model ini membangun pengetahuan dengan urutan proses yaitu meramalkan atau memprediksi solusi dari permasalahan, melakukan eksperimen untuk membuktikan prediksi, kemudian menjelaskan hasil eksperimen yang diperoleh secara lisan maupun tertulis, membuat contoh penerapan dalam kehidupan seharihari, menuliskan hasil 
diskusi dan memuat evaluasi tentang pemahaman peserta didik baik secara lisan maupun tertulis (Nana et al., 2014). Sintaks dari model POE2WE sebagai berikut:

a) Prediction

Tahap prediction yaitu siswa membuat prediksi atau dugaan awal terhadap suatu permasalahan. Permasalahan yang ditemukan berasala dari pertanyaan dan gambar tentang gerak lurus oleh guru yang ada di LKS/buku siswa sebelum siswa membuat prediksi. Pembuatan prediksi jawaban tahap Prediction pada model POEW identik dengan fase Engagenent pada pendekatan konstruktivistik. Guru mengajukan pertanyaan yang dapat mendorong siswa untuk dapat membuat prediksi atau jawaban sementara dari suatu permasalahan.

b) Observation

Tahap Observation yaitu untuk membuktikan prediksi yang telah di buat oleh siswa. Siswa diajak melakukan eksperimen berkaitan dengan masalah atau persoalan yang di temukan. Selanjutnya siswa mengamati apa yang terjadi, kemudian siswa menguji kebenaran dari dugaan sementara yang telah dibuat. Tahap Observation pada model POEW identik dengan fase Exploration pada pendekatan konstruktivistik.

c) Explanation

Tahap Explanation atau menjelaskan yaitu siswa memberikan penjelasan terhadap hasil eksperimen yang telah dilakukan. Penjelasan dari siswa dilakukan melalui diskusi dengan anggota kelompok kemudian tiap kelompokn mempresentasikan hasil diskusinya di depan kelas. Jika prediksi yang di buat siswa ternyata terjadi di dalam eksperimen, maka guru membimbing siswa merangkum dan memberi penjelasan untuk menguatkan hasil eksperimen yang dilakukan. Namun jika prediksi siswa tidak terjadi dalam eksperimen, maka guru membantu siswa mencari penjelasan mengapa prediksi atau dugaannya tidak benar. Tahap explanation identik dengan fase explanation pada pendekatan konstuktivistik.

d) Elaboration

Tahap elaboration yaitu siswa membuat contoh atau menerapkan konsep dalam kehidupan sehari-hari. Tahap elaboration di ambil dari pendekatan konstruktivistik. Tahap ini guru medorong siswa untuk menerapkan konsep baru dalam situasi baru sehingga siswa

lebih memahami konsep yang di ajarkan guru. Tahap ini pengembangan dari pendekatan konstruktivistik.

e) Write

Tahap write atau menulis yaitu melakukan komunikasi secara tertulis,merefleksikan pengetahuan dan gagasan yang dimiliki siswa. Menurut Masingilia dan Wisniowska (1996) dalam Ansari (2012) menulis dapat membantu siswa untuk mengekspresikan pengetahuan dan gagasan mereka. Siswa menuliskan hasil diskusi dan menjawab pertanyaan yang ada pada LKS. Selain itu pada tahap write ini, siswa membuat kesimpulan dan laporan dari hasil eksperimen. Tahap ini merupakan pengembangan dari model TTW.

f) Evaluation 
Tahap Evaluationyaitu evaluasi terhadap pengetahuan, keterampilan dan perubahan proses berfikir siswa. Pada tahap ini siswa di evaluasi tentang materi gerak lurus berupa lisan maupun tulisan.Tahap ini merupakan pengembangan dari pendekatan konstruktivistik. Penggabungan tahap-tahap model POEW dan pendekatan konstruktivistik.

\section{B. Penggunaan Mind Mapping pada proses pembelajaran sains}

Mind mapping bisa disebut sebagai sebuah peta rute yang menggunakan seluruh potensi otak agar optimum. Mind mapping melatih otak untuk melihat secara menyeluruh sekaligus secara terperinci dan dengan mengintegrasikan antara logika dan imajinasi. Bentuk mind map seperti peta sebuah jalan di kota yang mempunyai banyak cabang sehingga bisa membuat pandangan secara menyeluruh tentang pokok masalah dalam suatu area yang sangat luas, merencanakan sebuah rute yang tercepat dan tepat serta mengetahui kemana kita akan pergi dan dimana kita berada. Selain itu, mind mapping juga melibatkan kedua belahan otak dengan cara mengintegrasikan antara logika dan imajinasi sehingga akan memudahkan seseorang untuk mengatur dan mengingat segala bentuk informasi, baik secara tertulis maupun secara verbal. Selain itu, adanya kombinasi warna, simbol, bentuk, dan sebagainya memudahkan otak untuk menyerap informasi yang diterima. Implementasi mind mapping dalam kegiatan pembelajaran diharapkan mampu mengoptimalkan kemampuan otak anak, melatih untuk berpikir kritis dan inovatif, serta menumbuh kembangkan nilai-nilai karakter positif dalam diri seorang anak.

Berdasarkan hasil kajian pustaka di atas, terlihat bahwa ada banyak manfaat yang dapat diperoleh dari penerapan mind mapping. Salah satu yang paling menarik adalah bahwa mind mapping menyeimbangkan kedua belahan otak, yaitu logika dan imajinasi. Sebagaimana yang kita ketahui bersama bahwa otak kiri bertanggung jawab terhadap logika sedangkan otak kanan bertanggung jawab terhadap imajinasi dan seni sehingga melalui implementasi mind mapping, peserta didik dapat menghasilkan lebih banyak ide, pembelajaran menjadi menyenangkan, dan memudahkan dalam memahami materi pelajaran.

Menurut Nirmalasari (2011), kinerja antara otak kanan dan otak kiri yang tidak seimbang mengakibatkan peserta didik menjadi sulit untuk memahami materi pelajaran yang diberikan oleh guru. Implementasi mind mapping sangat sederhana. Bahan-bahan yang diperlukan untuk membuat mind map adalah kertas kosong tak bergaris, pena dan pensil warna, otak, dan imajinasi. Adapun cara untuk membuat mind map menurut Buzan yaitu: (a) mulailah dari tengah kertas kosong yang sisi panjangnya diletakkan mendatar, karena memulai dari tengah memberi kebebasan kepada otak untuk menyebar ke segala arah dan untuk mengungkapkan dirinya dengan lebih bebas dan alami; (b) gunakan gambar atau foto untuk ide sentral, karena sebuah gambar bermakna seribu kata dan membantu kita menggunakan imajinasi. Sebuah gambar sentral akan lebih menarik, membuat kita tetap terfokus, membantu kita berkonsentrasi, dan mengaktifkan otak kita; (c) gunakan warna, karena bagi otak, warna sama menariknya dengan gambar. Warna membuat mind map lebih hidup, menambah energi kepada pemikiran kreatif, dan menyenangkan; (d) hubungkan cabang-cabang utama ke gambar pusat dan hubungkan cabang-cabang tingkat dua dan tiga ke tingkat satu dan dua, dan seterusnya. Karena otak bekerja menurut asosiasi. Otak senang mengaitkan dua (atau tiga, atau empat) hal 
sekaligus. Bila kita menghubungkan cabang-cabang, maka kita akan lebih mudah mengingat dan mengerti; (e) buatlah garis hubungan yang melengkung, bukan garis lurus, karena garis lurus akan membosankan otak; (f) gunakan satu kata kunci untuk setiap garis, karena kata kunci tunggal memberi banyak daya dan fleksibilitas kepada mind map; dan (g) gunakan gambar, karena seperti gambar sentral, setiap gambar bermakna seribu kata (Buzan, 2005). Implementasi mind mapping secara langsung dapat diberikan dengan meminta siswa membuat mind map untuk menyelesaikan permasalahan yang dikaji ataupun dengan menampilkan mind map buatan guru/dosen.

C. Penerapan model POE2WE pada model Mind Mapping

\begin{tabular}{|c|c|}
\hline Sintaks & Kegiatan pembelajaran \\
\hline Prediction & $\begin{array}{l}\text { Dengan membuat dugangan awal terhadap suatu } \\
\text { permasalahan. Permasalahan yang ditemukan berasal dari } \\
\text { pertanyaan dan gambar tentang mind mapping. Siswa } \\
\text { diberikan contoh tentang suatu topik sains . siswa memberi } \\
\text { sebuah prediksi terlebih dahulu dan jawaban semestara. Guru } \\
\text { bertanya mengenai topik sains tersebut }\end{array}$ \\
\hline Observation & $\begin{array}{l}\text { Membuktikan prediksi yang telah dibuat oleh siswa dengan } \\
\text { media mind mapping. Guru mencontohkan subuah } \\
\text { permasalahan topik sains seorang anak tersebut lalu diikuti } \\
\text { oleh siswa. Lalu siswa menguji kebenaran dari dugaan dan } \\
\text { prediksi yang telah ia buat. Dengan hasil mind mapping yang } \\
\text { menarik sehingga mudah untuk dipahami. Setelah siswa } \\
\text { memahami cara kerja metodemind mapping, guru } \\
\text { memberikan beberapa materi pembelajaran dan meminta } \\
\text { siswa melakukan nya dengan menulis sebuah mind mapping } \\
\text { untuk mencari tahu hasil dari keadaan yang mereka berikan. } \\
\text { Proses ini dapat dikatakan bahwa siswa melakukan simulasi } \\
\text { dari keadaan yang terjadi pada hal yang nyata. }\end{array}$ \\
\hline Eksplanation & $\begin{array}{l}\text { Pada tahap ini pertama-tama guru menjelaskan cara kerja } \\
\text { mind mapping dan jenisnya lalu guru memberikan penjelasan } \\
\text { tentang topik yang akan ditulis untuk mind mapping. lalu } \\
\text { siswa melakukan diskusi dengan masing-masing } \\
\text { kelompoknya untuk membuktikan prediksi mereka yang } \\
\text { diawal dengan eksperimen baru yang diberikan oleh guru } \\
\text { berdasarkan materi dan teori. }\end{array}$ \\
\hline Elaboration & $\begin{array}{l}\text { Guru memberikan contoh pada tumbukan dikehidupan } \\
\text { sehari-hari agar siswa tidak hanya memikirkan bentuk dan }\end{array}$ \\
\hline
\end{tabular}




\begin{tabular}{|c|l|}
\hline & $\begin{array}{l}\text { jenis saja pada metode mind mapping tetapi siswa dapat } \\
\text { mengetahui keadaan suatu materi pada kehidupan sehari-hari } \\
\text { juga siswa dapat lebih memahami konsep. }\end{array}$ \\
\hline Write & $\begin{array}{l}\text { Siswa mulai menuliskan mind mapping dari materi yang } \\
\text { sudah diberikan. Mereka membuat materi dari beberapa } \\
\text { keaadaan masalah yang diberikan oleh guru. }\end{array}$ \\
\hline Evaluation & $\begin{array}{l}\text { Setelah siswa selesai membuat mind mapping, siswa diberi } \\
\text { beberapa soal analisis untuk melakukan analisis dari semua } \\
\text { materi yang telah diberikan. Mereka memberikan beberapa } \\
\text { argumen dari materi tersebut sesuai dengan teorinya. }\end{array}$ \\
\hline
\end{tabular}

Berdasarkan tabel tersebut, model POE2WE dapat dikombinasikan dengan metode mind mapping yang secara garis besar merupakan suatu pemetaan berdasarkan sebuah teori pembelajaran agar siswa dapat dengan mudah menggunakannya sebagai bahan belajar. Model POE2WE yang berbentuk sistematis dapat membuat metode mind mapping menjadi lebih struktural dalam penyusunannya.

\section{Kesimpulan}

Berdasarkan pengolahan data dan pembahasan hasil penelitian yang dilakukan, dapat ditarik kesimpulan sebagai berikut. (1) Model $\mathrm{POE}_{2} \mathrm{WE}$ efektif sebagai model yang bisa digunakan untuk media mind mapping. (2) model mind mapping efektif sebagai penunjang siswa untuk melakukan proses pembelajaran. Dalam perkembangan ilmu sains dibutuhkan suatu model yang dapat menjadi penyeimbang dalam melakukan sebuah metode terutama mind mapping yang merupakan pemetaan suatu topik pembelajaran. Model POE2WE berdasarkan teori yang diambil dari berbagai sumber, merupakan model yang tepat untuk diterapkan dalam metode mind mapping untuk meningkatkan pembelajaran dalam proses sains.

\section{DAFTAR PUSTAKA}

Buzan, T. 2005. Buku Pintar Mind Map. Jakarta: PT. Gramedia Pustaka Utama.

Delors et.al. 1996. International Commission on Education for the 21st Century. Learning: The Treasure Within. Paris: Unesco Publising.

Depdiknas. 2007. Materi Sosialisasi KTSP. Jakarta: Depdiknas.

Eka Pratiwi Tenriawaru.(2014). Implementasi Mind Mapping dalam Kegiatan Pembelajaran dan Pengaruhnya terhadap Pendidikan Karakter. Volume 01, Nomor 1. Hal 88 dari 214 
Jeremy, E.C. 2005. Why Educational Innovations Fail: An Individual Difference Perspective. "Cleveland State University" Journal Vol. 332005.

Nana, dkk. (2014). The Development Of Predict, Observe, Explain, Write, and Evaluate $\left(\mathrm{POE}_{2} \mathrm{WE}\right)$ Learning Model in Physics Leraning At Senior Secondary SchoolJournal Of Education And Practice- Vol.6 -No.19.

Nana, (2018). IMPLEMENTASI MODEL POE2WE DENGAN PENDEKATAN SAINTIFIK DALAM PEMBELAJARAN GERAK LURUS DI SMA. file:///C:/Users/hp/Downloads/12477-26039-1-SM.pdf

Nirmalasari, M. 2011. Pengembangan Model Momorization Learning dalam Meningkatkan Pemahaman Peserta Didik pada Pelajaran Kimia SMA. Jurnal Penelitian Pendidikan, Edisi Khusus Nomor 2 Agustus 2011.

O’Malley, J. M., \& Pierce, L. V. 1996. Authentic Assessment for English Language Learners: Practical Approaches for Teachers. New York: Addison-Wesley Publishing Company.

Taufik Mohammad, dkk. (2010).DESAIN MODEL PEMBELAJARAN UNTUK MENINGKATKAN KEMAMPUAN PEMECAHAN MASALAH DALAM PEMBELAJARAN IPA (FISIKA) SEKOLAH MENENGAH PERTAMA DI KOTA BANDUNG. Vol 13. , No.2, Edisi khusus April 2010, hal E31-E44 